Perspectiva Geográfica ISSN 0123-3769

Vol. 15/2010; pp. 143-156

\title{
El ordenamiento territorial en Colombia a través del tiempo
}

\author{
Zoning in Colombia throughout time
}

\author{
Mauricio Villamil Pérez*
}

\section{Resumen}

Comprender la situación de Colombia en materia de ordenamiento, considerando que este es un país agobiado por una violencia histórica enfocada hacia el control y dominio territorial, ya sea por afán de lucro o simplemente por control político, es un proceso que debe realizarse consustancialmente con los hechos históricos que la acción humana desarrolla en su afán de adaptabilidad territorial, y que a través del tiempo lo construye social, política y culturalmente en la búsqueda de un modelo equilibrado.

Palabras clave: Ordenamiento Territorial, Urbanismo.

\section{Abstract}

Understanding the situation in Colombia in terms of territorial management, planning and zoning, considering that this is a country burdened by a history of violence focused on territorial control and domination, whether for profit or simply for political control, is a process which must be made taking into consideration the historical fact that human action in an effort to develop regional adaptability, and over time as socially constructed, is politically and culturally in the search for a balanced model.

Key words: Territorial Management, Urban Planning, Zoning.

* Magíster en restauración de monumentos arquitectónicos. Gerente Arcad Arquitectos R\&V Ltda. mauriciovillamilperez@hotmail.com 


\section{Introducción}

Determinar la existencia de un ordenamiento en el actual territorio de Colombia, a similitud del resto de Hispanoamérica, ha sido el resultado de una rápida evolución histórica dinamizada desde finales del siglo XIX, cuando bajo diversas determinantes de índole social, político y económico los principales núcleos urbanos comenzaron a establecer sus características actuales. Algo similar ocurrió con las áreas rurales, que de uno $\mathrm{u}$ otro modo se vienen a articular con las urbanas, interactuando y determinándose mutuamente. En nuestros días, este hecho obedece a una serie de variables internas y externas, principalmente de orden económico, que serán analizadas en este artículo, pero en un principio obedeció a un sistema bajo el cual se ordenaron y repartieron los diferentes territorios caídos bajo el dominio del que llegaría a ser el poderoso imperio español.

En el desarrollo del tema se pretende explicar cómo la ciudad colombiana es consecuencia de un proceso histórico, evolutivo, en el cual la base primordial ha sido el conflicto y el dominio territorial, lo cual ha llevado a una sucesión de precarios tejidos habitacionales sin ningún tipo de infraestructura, y de elementos que no definen una imagen urbana, sumado al hecho de que no se vislumbra una perspectiva de desarrollo.
Ahora bien, teniendo en cuenta que en la actualidad el ordenamiento territorial se plantea como una normativa que regula el uso del territorio, es importante considerar el modelo de ocupación y explotación que se ha dado de él, y que da origen al prototipo de ciudades. En este sentido, los nuevos criterios de ordenación y desarrollo deben soportarse en el entendimiento de la sociedad, las formas y modelos de ocupación que se han dado, para que se plante un futuro acorde con las condiciones ya establecidas, es decir, fortalecer la identidad; no obstante, brindando una paulatina continuidad a los proyectos socio-económicos, evitando en lo posible la implantación de modelos foráneos que obstruyan la construcción de país.

\section{El primer ordenamiento territorial como aplicación de una política imperial}

Retrocediendo en el tiempo, es preciso aclarar cómo el ordenamiento territorial indiano, impuesto desde el siglo XVI, no propiamente español, pues en la península no se utilizó, obedeció a un método de reparto de tierras aplicado desde la antigüedad y expandido principalmente por los romanos, a quienes habían precedido pueblos conquistadores de Asia menor en sus fundaciones.

De esta manera, no por azar, cuando se comenzaron a expedir las leyes de indias ${ }^{1}$,

\footnotetext{
“... Las Leyes de Indias comprenden reales cédulas, reales órdenes, pragmáticas, provisiones, autos, resoluciones, sentencias y cartas, obligándose a la confirmación por el Rey de cualquier disposición dictada por otra persona u organismo.

Si bien el fin religioso es una de las preocupaciones principales de la Corona, no es menos cierto el riguroso respeto por "el orden y forma de vivir de los indios, siempre que no estuvieran en rigurosa contradicción con los principios básicos de la legislación española" (Ley 22, título $2^{\circ}$ del Libro V de las Disposiciones de Carlos I). Así, en la Ley $4^{\mathrm{a}}$, título $1^{\circ}$, Libro II de las Recopilaciones de 1680 se lee: "Ordenamos y mandamos que las leyes y buenas costumbres que antiguamente tenían los indios para su buen gobierno y policía, y sus usos y costumbres observadas después que son cristianos, y que no se encuentran en nuestra religión, se guarden y ejecuten". (www.es.wikipedia.org/wiki/Distrito del Ensanche (obtenido en octubre de 2010).
} 
tanto en lo territorial como en lo concerniente al trato hacia los pobladores, quienes asesoraron a los monarcas Carlos I y Felipe II, y ellos mismos con visión imperial, en procura de controlar a los nuevos súbditos, así como de cuantificar el inmenso continente que se abría al otro lado del océano, adoptaron la cuadrícula en fanegas, que no se limitaba a los núcleos urbanos, sino que actuaba como trazado único de repartición territorial. La concepción imperial llevaba implícito el hecho de ser de fácil aplicación este sistema, asemejado a un lenguaje universal.

Aquí es preciso hacer notar cómo España, o más concretamente Castilla, aparecía en Europa como el primer Estado-nación moderno de aquel continente, muy diferente del Estado-ciudad de la Edad Media, que aún predominaba, pero a América, extrañamente, se trasladó un esquema de dominación por mandato fundado en la noción del "privilegio" que el rey concedía bajo diversas figuras a "los adelantados" o quienes "están delante", haciendo relación a los territorios lejanos o "de frontera" que les habían sido concedidos para su explotación.

Este esquema de reparto y de poblamiento urbano, si bien claro, no fue bien acogido por quienes protagonizaron las primeras décadas de sometimiento en el nuevo mundo, ya que se trataba en su mayor parte de aventureros que "llevaban la casa a cuestas" y no tenían vocación colonizadora, cuyas hazañas y ambición parecían no tener fin, persiguiendo fabulosos reinos.

El necesario asentamiento de colonizadores determinó que en aquel lejano siglo XVI se expidiera el primer ordenamiento territorial, para evitar que las fundaciones no fueran abandonadas por sus pobladores, lo que se había hecho frecuente. Así, en el temprano año de 1526, Carlos I expidió la Real Cédula del 17 de noviembre que "ordenaba a los oidores, gobernadores para que los vecinos casados en ellos no las abandonen por el atractivo de nuevos descubrimientos so pena de muerte". Y otra expedida el 15 de enero de 1529 que ordena a cada uno de los vecinos "declarar ganados $o$ dependencias para que se abstengan de nombrar o conquistar por vía de colonia o capitulación" (Capdequí, 1946). De esta forma, tímidamente y pese a lo que ligeramente pueda considerarse, mediante el empadronamiento y la sujeción a la tierra de los colonizadores se gestaba un primer ordenamiento territorial.

Más tarde, con las ordenanzas reales de Felipe II, expedidas en el año de 1573, se daba a los adelantados "la facultad de repartir tierras y solares”; además, en un primer avance hacia la noción de "valorización" de estas tierras, "se implantó el sistema de enajenar las tierras en pública subasta, adjudicándolas al mejor postor" (Capdequí, 1946).

\footnotetext{
Por ejemplo: "Jiménez de Quesada tiene títulos como Capitán General, Teniente General. También fue llamado el Licenciado o el Adelantado. Algunos historiadores advierten que el título de Teniente General lo recibió en las islas Canarias, sin embargo, esto es discutible ya que éste, por jerarquía, le debía corresponder a Luis de Lugo, hijo de Pedro Fernández de Lugo. Allí, el título más apto para Jiménez de Quesada debía ser Justicia Mayor por ser abogado" (Castillo, 2006).
} 
También, con una "intención funcional" se disponían estas "ciudades-territorio", donde estaban claramente jerarquizados los edificios y los pobladores: en torno de la plaza mayor estaban los edificios "edilicios", pertenecientes al cabildo, los regidores y autoridades; la cárcel y, en lugar principal, con "valor escenográfico", el templo. Este último poseía un valor único y actuaba enfrente de toda la población a manera de "aglutinador"; era sin duda el símbolo máximo de este modelo de ciudad, con caracterizaciones tanto externas como internas únicas.

La plaza actuaba a manera de "medidor del control social-racial"; en los solares y manzanas anexas se situaban los habitantes principales, a quienes seguían los artesanos $\mathrm{y}$, exteriormente localizados, no del todo regularmente, los indígenas. Irónicamente, los indígenas, habituados a la tan aludida "vida externa", eran quienes más permanecían en la plaza mayor, donde además se celebraba el mercado, así como en las calles, de lo que incluso viajeros llegados en épocas posteriores a la Colonia dan fe.

Otro de los elementos invariables, de ninguna manera dispuestos al azar, eran los conventos, que albergaban las pilas de agua, la escuela y la botica, además de otros servicios para la comunidad, como el hospicio para pobres, expósitos y desamparados, y el hospital. Estos conventos poseían una extensión de tierra considerable, que actuaba a manera de primer anillo controlador territorial periférico. A estas tierras se les daba el nombre de "abadales" o "abalengas", permanecían en torno de los asentamientos como límites urbanos y se integraban sin escisiones con las áreas no urbanizadas; allí "la vegetación penetra sin solución de continuidad, sin generar ruptura alguna" (Gutiérrez, 2002).

A las tierras así controladas seguían los reales "egidos", terrenos pertenecientes al Rey dispuestos a lo largo de los caminos de acceso a manera de reserva para el futuro desarrollo urbano, de los que no se podía disponer y que actuaban como un segundo anillo de control para el crecimiento territorial. Es claro, entonces, el hecho de no requerirse de espacios verdes externos, pues estos existían tanto en el interior de las manzanas, como a escasa distancia de las áreas urbanizadas. Por otra parte, al no existir o ser muy limitados los vehículos de tracción humana y animal, se estipulaba el clima como controlador de la amplitud de las calles, debiendo de ser "angostas en los lugares cálidos para proveer de sombra, y amplias en los lugares fríos".

El paisaje urbano derivado de este esquema resulta claro, la convivencia de pobladores autóctonos con foráneos, lo que se reflejaba igualmente en las técnicas constructivas utilizadas, muy similar a lo sucedido en las áreas rurales, donde hacían lo propio especies vegetales y animales, aun cuando detentadas en su mayor parte por las respectivas comunidades.

Como una primera conclusión se puede plantear este como el primer esquema de ordenamiento territorial, en apariencia 
solo de reparto y con una clara intención panóptica, que con toda la sucesión de normas adicionales se constituye en un sistema complejo de expresión múltiple, aunque su apariencia sea similar, y que pese a su configuración ortogonal su intención es claramente renacentista, "donde la plaza actúa como centro cívico renacentista, unido a la experiencia medieval del mercado y el súbdito de vida externa indigena" (Gutiérrez, 2002).

En esto se destaca cómo la expresión múltiple de esta ciudad ortogonal obedece a que esta parte de la plaza central varía de uno a otro lugar en aspectos como las dimensiones de las manzanas, la amplitud de las calles, la existencia de aleros, atrios, fuentes, arcadas, pasajes y espacios abiertos enfrente de los edificios principales, así como en el progresivo enlucimiento y características de las edificaciones en proporción directa a la jerarquía del asentamiento convertido en ciudad.

En algunos casos, como referente de la antigüedad, como de las aludidas determinantes de orden climático, algunas de las vías de estas ciudades se vieron rodeadas de edificaciones con columnas, perfil seguido hasta el mismo siglo $\mathrm{xx}$, y cuyo caso más representativo es el de $\mathrm{La}$ Habana.

Un punto en el que se debe hacer énfasis es que este primer modelo de ordenamiento territorial, con todos los elementos que involucra y como frecuentemente se ha descrito, no fue resultado de una concepción ideal, sino que fue concebido minuciosamente en conjunto, partiendo de referentes históricos claros y con la visión imperial que tuvieron durante el siglo xvi los dos primeros "Habsburgos" 3 al frente del imperio español, ingrediente del que carecieron sus sucesores durante la centuria siguiente, cuando comenzó la larga decadencia de este imperio.

Pese a que el tema gira en torno a la organización del territorio, una pieza de gran importancia que raramente se ha analizado, y lo que después no volverá a suceder, es que a partir de los desmanes cometidos por los primeros conquistadores en América, la legislación indiana consideró la protección de los pobladores en sus

“(...) La Casa de Austria es el nombre con el que se conoce a la dinastía Habsburgo reinante en la Monarquía Hispánica en los siglos XVI y XVII; desde la Concordia de Villafáfila (27 de junio de 1506) en que Felipe I el Hermoso es reconocido como rey consorte de la Corona de Castilla, quedando para su suegro Fernando el Católico la Corona de Aragón; hasta la muerte sin sucesión directa de Carlos II el Hechizado (1 de noviembre de 1700), que provocó la Guerra de Sucesión Española. El Emperador Carlos V (Carlos I de España) acumuló un enorme complejo territorial y oceánico sin parangón en la historia, que se extendía desde Filipinas al este hasta México al oeste, y desde los Países Bajos al norte hasta el Estrecho de Magallanes al sur. Además de la expansión ultramarina, y algunas conquistas (como Milán), fue resultado de la adición dinástica de cuatro casas europeas: las de Borgoña (1506), Austria (1519), Aragón (1516) y Castilla (1555), y conformó la base de lo que se conoció como Imperio español, sobre todo a partir de la división de su herencia (1554-1556) entre su hermano Fernando I de Habsburgo y su hijo Felipe II. Desde entonces puede hablarse de dos ramas de la casa de Austria, los Habsburgo de Madrid (que son los de los que trata este artículo) y los Habsburgo de Viena (que continuaron reinando en Austria hasta 1918). La Monarquía Hispánica (también conocida como Monarquía Católica) fue durante toda esa época la mayor potencia de Europa. Durante los Ilamados Austrias mayores (Carlos I y Felipe II) alcanzó el apogeo de su influencia y poder, sobre todo con la incorporación de Portugal y su extenso imperio; mientras que los reinados de los llamados Austrias menores (Felipe III, Felipe IV y Carlos II), coincidentes con lo mejor del Siglo de Oro de las artes y las letras, significaron lo que se conoce como "decadencia española": la pérdida de la hegemonía europea y una profunda crisis económica y social. (...)" (http:// es.wikipedia.org/wiki/Casa_de_Austria). 
diversas variedades, poniendo especial énfasis en los nativos; esto, pese a haber sucedido hace tanto tiempo, según quienes se han encargado del tema, ha sido " $\mathrm{el}$ mayor intento en cuanto a la protección de los derechos humanos se trata" . Como se verá, en adelante se atenderá, o se hará caso de la población únicamente cuando esta, deprimida, es vista como una amenaza.

Ahora bien, durante la dilatada presencia del imperio español en América, regentado luego por los Borbones, debido al progresivo mestizaje, al control político y a la existencia de grandes bloques que deseaban predominar sobre el continente, así como a la noción impuesta sobre el carácter virtualmente "sagrado" de las autoridades constituidas, no se tiene conocimiento de la existencia de crisis alguna de los esquemas impuestos, lo que rápidamente se habrá de invertir, cuando la mayor parte de estos elementos aglutinantes fueron sustituidos por un frágil régimen de inspiración republicana ${ }^{5}$.

Otro factor que determinó el equilibrio de este esquema urbano y el entorno fue el control del comercio y del ingreso de personas, ganados y de rentas por las autoridades coloniales, lo que controlaba efectivamente la cantidad de habitantes, medidas establecidas sin duda con orden político.

Por lo demás, si bien existían poseedores de grandes extensiones de tierra, denominadas "mayorazgos", bajo la administración colonial existían resguardos y predios de mediana extensión y autosuficientes que pagaban tributo, y cuyo censo se llevó medianamente a cabo a finales del siglo xvIII, cuando el marqués de la Ensenada determinó elaborar el catastro de los predios situados en la península y en América. De este modo, debido tanto al esquema político como a la inexistencia de un verdadero capitalismo, los esquemas culturales urbano y rural pudieron convivir largamente, y solo los hechos ocurridos desde finales del siglo XVIII y comienzos del siguiente forzaron la ruptura de este equilibrio, surgido de la imposición de una nación convertida en potencia colonizadora, y lo que no precisó de adaptaciones a través del tiempo.

Así, con las reales ordenanzas de 1573 concluyó lo concerniente a este proceso de regularización urbana; más tarde, en 1680,

$\overline{4}$ Cita contextual formulada por José María Ots Capdequí, en varias de sus obras alrededor del derecho indiano.

5 “(...) Para esta época nace la Gran Colombia que llega a su fin en 1830 por conflictos y divisiones internas de los caudillistas. Tras muchas reformas territoriales y políticas, Colombia recibe su nombre actual en 1886: República de Colombia. En 1830 se da por terminada La Gran Colombia, desintegrada por divisiones internas y conflictos entre los caudillos de la época, más exactamente por la división de la población entre liberales y conservadores. Sin embargo, aun después del fin de la Gran Colombia y el surgimiento de la nueva República de Colombia, la vida del país en el siglo XIX sigue transcurriendo en una sucesión de enfrentamientos, no sólo entre liberales y conservadores, sino también entre bolivarianos y santanderistas; artesanos y librecambistas; federalistas y centralistas; terratenientes, esclavos y aparceros; clericales y radicales, que dan lugar a muchos más conflictos civiles. El desorden institucional existente para ese momento, dentro del cual se presentaba una quiebra de la Hacienda Pública y las ya mencionadas rivalidades entre caudillos, se pudo controlar un poco gracias a la creación de la Constitución de 1886, la cual canceló el federalismo definitivamente y fortaleció el poder central, siendo Rafael Núñez su principal gestor, al encabezar el movimiento de la "Regeneración". Sin embargo, las garantías democráticas quedaron suspendidas y la persecución contra los radicales llevó a una de las guerras civiles más sangrientas que ha enfrentado el país denominada "Guerra de los Mil Días" (1989 - 1902), en mitad de la cual se inicia el siglo XX, derrotando al partido liberal. Con ésta se consolida el bipartidismo liberalconservador". (http://es.wikipedia.org/wiki/Historia_de_Colombia) 
estas fueron compiladas en extenso, bajo el reinado de Carlos II, y posteriormente, en 1805, cuando los avances de la invasión napoleónica en Europa presagiaban el fin de los órdenes establecidos.

\section{El colapso de un sistema y primeras políticas al respecto; el urbanismo especulativo}

Se han cumplido 200 años de las primeras declaraciones de independencia hechas sobre suelo americano, en su mayor parte por voz de los criollos de las élites, las cuales conducirían, una década más tarde, al rompimiento de un orden que largamente había predominado, y con ello al derrumbe de la casi totalidad de los símbolos y esquemas que hasta entonces habían predominado. En un comienzo, los hechos recientemente conmemorados a lo largo del continente no presagiaban lo que poco después habría de precipitarse, sino, más bien, la necesaria actualización de mucho de lo que tanto tiempo había predominado; pero las nuevas generaciones, muchas de ellas influidas por las doctrinas liberales, lo que verdaderamente deseaban, con ligeras variaciones, era la subrogación de los poderes y funciones imperantes.

Es claro el hecho de que muchos de los protagonistas de estas declaraciones y luchas de independencia pertenecían a segmentos poseedores de medios económicos, lo que les había permitido instruirse y viajar a Europa y Norteamérica, pero esto solo vino a pesar ligeramente en lo que respecta a la evolución de los esquemas urbanos implantados, muchos de ellos inspirados y portadores de "ideales", en este caso sí vale el término, de justicia social y digno emplazamiento de los pobladores.

Dentro del orden de hechos que rápidamente se sucedieron, incluido el territorio del antiguo reino de Granada, se produjeron, por una parte, el desplazamiento de parte de los pobladores, por ser afectos al Rey, y, por otra, las primeras guerras entre las facciones, en nuestro caso entre centralistas y federalistas; esto porque había sucedido un hecho por pocos hasta hoy considerado, pero que explica buena parte de lo ocurrido con posterioridad: la pérdida del control político, que solo se restablecerá medianamente a comienzos del siglo xx.

Inmediatamente después de la finalización de las guerras de independencia, cuando el proyecto republicano como entidad autónoma comenzó a hacerse realidad, vinieron dos hechos que habrían de pesar en el ordenamiento territorial: la desactivación de los ejércitos que habían participado en las guerras y el pago de las recompensas ofrecidas a quienes participaron en las confrontaciones de liberación (Santa, 1995). Lo primero hizo que se originara un panorama urbano hasta entonces desconocido, y que habría de sucederse a lo largo de todo el siglo XIX, como lo fueron los veteranos de guerra que, desactivados, quedaron inmovilizados en los incipientes centros urbanos sin poder regresar a sus lugares de origen. En cuanto al pago de recompensas, se recurrió para ello a los 
grandes territorios baldíos, como a otros abandonados por los realistas, lo que dio origen a un acceso masivo de nuevos pobladores a estas tierras; sin duda, el más significativo de estos movimientos de masas humanas fue el conocido como "la colonización antioqueña", en virtud del cual se produjo una cantidad significativa de nuevos asentamientos que vinieron a configurar, al finalizar el siglo XIX, un nuevo paisaje urbano y rural, que habría de hallar su punto de sustentación económica en el café y en la diversidad de cultivos y de actividades agropecuarias que se generaron de manera progresiva alrededor de este producto (Santa, 1995).

Pero mientras esto último ocurría, dentro de un proceso que únicamente se ha estudiado de manera parcial, ¿qué ocurría con los ya seculares asentamientos establecidos en su mayor parte durante la primera centuria del periodo colonial? Algunos de ellos fueron escenarios de enfrentamientos entre las facciones independista y realista, que les ocasionaron un marcado deterioro y que una gran cantidad de predios e inmuebles quedaran abandonados o en manos de un Estado que no sabía cómo disponer de ellos. Esto se hizo particularmente notorio en ciudades como Cartagena y Santa Marta, que como lo han hecho notar recientemente algunos tratadistas, solo vinieron a recuperarse a partir de nuevas actividades durante la segunda mitad del siglo $\mathrm{xx}^{6}$.
Algo similar había ocurrido con los que fueran predios de propiedad real, como los ejidos, dispuestos, junto con las propiedades de las comunidades religiosas, como reservas para controlar el crecimiento urbano, y cuyo desbordamiento habría de ponerse de manifiesto cuando en 1861 el gobierno de Tomás Cipriano de Mosquera decretó la desamortización de bienes de manos muertas, medida en virtud de la cual la mayor parte de los bienes bajo dominio de las comunidades religiosas fueron confiscadas por el Estado, cuya composición, denominación y funcionamiento a manera de un péndulo variaba sucesivamente, en la medida que se sucedían las tendencias que profesaban quienes se alternaban en el poder.

El Estado que se estaba configurando carecía de recursos, igualmente, los convertidos alternativamente en departamentos, que lo componían, no tenían capacidad de financiar obras públicas indispensables, como los puentes y los acueductos, que eran deficientes y construidos por particulares, en no pocos casos emparentados con los gobernantes de turno que los cedían para su explotación. Esto mismo ocurría con la moneda y el crédito público, para lo que se recurría a prestamistas particulares que suministraban monedas que tenían libre circulación tanto a nivel interno como en el exterior, para servir renglones como el reducido cuerpo diplomático acreditado en el exterior.

Cita contextual con referencia a varios artículos aparecidos en el diario El Espectador con motivo del bicentenario de la independencia, por los economistas Eduardo Meisel y Salomón Kalmanowitz, y en la serie de conferencias de índole económica celebradas en 2009 con igual motivo. 
Otro ingrediente que existe, y que sólo se ha abordado muy de lado, es la desarticulación de las regiones que se habían consolidado con una serie de características intrínsecas a lo largo del periodo colonial, dentro de lo que fue un imperio que, pese a muchos vicios, estaba claramente articulado en los más diversos aspectos, y que en menos de dos décadas se vio desmembrado en una serie de provincias regidas por caudillos enfrentados, cada una de ellas pugnando por ser reconocida e ingresar de alguna manera dentro del campo desconocido del concierto de las naciones. De esta manera se desarticularon todas las regiones que integradas habían tenido unidad durante el periodo colonial, y comenzaron a surgir otras, en mucho casos trazadas para servir intereses personales de los caudillos y determinadas bajo un orden político que tomaba un rumbo incierto, lo que, como era de esperar, habría de conducir a una profunda crisis en todos los órdenes, de lo que habrían de resultar nuevos contextos urbanos y rurales que precisarían de medidas y de modelos innovadores, muchos de ellos puestos en marcha tardíamente, y aún repercuten en nuestros días ${ }^{7}$.

A partir de los cambios que rápidamente tenían lugar, los antaño apacibles centros urbanos se vieron notoriamente acrecidos en su población, que rápidamente se multiplicó, asentándose en sucesivas subdivisiones hechas en los antiguamente amplios solares y en las áreas subnormales que, premonitoriamente, se iban asentando en las áreas periféricas.

Dentro de este orden de sucesos era apenas claro que pese a que se ampliara sucesivamente el tradicional trazado urbano, sus características no resultaban apropiadas para un medio en el que ya se anunciaban vehículos de tracción mecánica, nuevos espacios públicos al aire libre y cubiertos, centros fabriles y de abastecimiento, entre otros.

Tal como en efecto ocurrió, la superutilización del viejo esquema indiano condujo a su virtual explosión, obviamente "desde adentro", haciéndose visibles fallas que le eran inherentes y que superaban la escala para la que podía haber estado previsto; pero pese a ello se continuó usando, lo que bien puede explicar su predominio en la mayor parte de las ciudades donde se sobreexplotó este modelo, y donde además fueron suprimidos los elementos de control que lo limitaban y lo hacían viable.

A nivel nacional, con excepción de la ya aludida desamortización de bienes de manos muertas y del reparto de tierras a manera de recompensa a quienes tomaron parte activa y principal dentro de las guerras de independencia, no se encuentran documentos ni disposiciones oficiales en las que se exprese la voluntad por parte del Estado de un reparto $\mathrm{u}$ ordenamiento territorial acorde con la supuesta vocación republicana que había

Principalmente la función social de la tierra que se expresa en la Ley 200 de 1936 y en la Ley de reforma agraria expedida en el año de 1961 durante la administración de Alberto Lleras. 
sustituido a un régimen por muchos señalado como "tiránico". En lugar de ello, son notorias las hazañas llevadas a cabo por aventureros que, superando lo ocurrido en los primeros tiempos de la Conquista, se internaron en los hasta entonces inexplorados territorios de la cuenca amazónica y de los llanos orientales para explotar sin límites sus riquezas; uno de ellos fue el luego presidente de la república Rafael Reyes, que en nota autobiográfica narra su desempeño como cauchero en el Amazonas y el Putumayo. Por esta vía se originaron inhumanos medios de explotación, como los utilizados por la tristemente célebre "Casa Arana", de cuyas exacciones dieron nota el diplomático irlandés Roger Cesement y el novelista y poeta José Eustasio Rivera ${ }^{8}$.

Otro tanto, y con igual sentido de lucro, hicieron otros personajes que adquirieron a precios irrisorios grandes extensiones en proximidad de las áreas urbanas y que insospechadamente asistieron al comienzo de la especulación urbana característica de toda una época.

Hasta este punto es preciso señalar cómo hasta comienzos del siglo $\mathrm{xx}$, un Estado absolutamente subdesarrollado había carecido de personas capacitadas, así como de recursos para su mínimo desempeño, lo que sumado a una geopolítica inviable y a una serie de inútiles guerras civiles impidió cualquier tipo de avance en los diferentes órdenes $\mathrm{u}$ ordenamiento del territorio. Se "controlaba" virtualmente todo desde Bogotá, alejada de las costas y, desde luego, del mundo, aún más cuando las comunicaciones se limitaban a una incipiente red de telégrafos. La idea de orden y conexión del país y del territorio, planteada por los españoles, queda desarticulada.

Igualmente, esto condujo a hechos desastrosos, como la separación de Panamá, lo que de manera irónica provocó que dos décadas más tarde, con la llegada de la suma por concepto de indemnización de la zona del canal, comenzara la prosperidad a debe, y con ello se iniciara un precario "progreso" 9 .

Es importante señalar aquí cómo en el año 1925 (Acuerdo 74), inspirándose al parecer en planes de ensanche, como el llevado a efecto con anterioridad por Ildefonso Cerdá en Barcelona ${ }^{\mathbf{1 0}}$, el Concejo de Bogotá

8 Como ejemplo, retomo la novela denominada "La Vorágine", escrita en 1924, en la cual "se relata en primera persona la aventura de Arturo Cova, quien huye de las convenciones sociales de la estrecha sociedad colombiana de principios del siglo XX. Esa huida lo lleva a los llanos orientales, extensa región de caudalosos ríos, donde se separa intempestivamente de Alicia, su compañera. La búsqueda de Alicia lo llevará a la selva de la Amazonía colombiana, donde Arturo será testigo de la penosa esclavitud de los trabajadores que extraen el caucho para la casa peruana Arana. La selva, sus ritos ancestrales y sus alucinaciones, y la lucha incansable por sobrevivir en ella son los protagonistas de esta novela que narra además la tragedia social que recuerda la que actualmente padece Colombia" (http://es.wikipedia.org/wiki/Jos\%C3\%A9_Eustasio_Rivera).

9 De ello se derivaron principalmente entidades sugeridas por la misión Kemmerer como el Banco Central y la Contraloría General.

10 "(...) Durante la primera mitad del siglo xix en pleno auge de la Revolución industrial, las ciudades que hasta entonces continuaban teniendo un urbanismo Medieval, muchas de ellas rodeadas de murallas, se ven colapsadas por la instalación de las recién nacidas industrias y la expansión demográfica. 
presentó un plan urbano denominado "Bogotá Futuro", consistente en multiplicar por cuatro el área urbana, conectando los principales puntos, plazas, almacenes y áreas de abastecimiento a partir de una serie de diagonales interconectadas por medio de glorietas. Por supuesto, este plan tan ambicioso no se llevó a efecto, pero apenas una década más tarde, de manos de un reconocido urbanista, se trazaron algunas urbanizaciones y se "regularizaron" sectores deprimidos, todo ello obedeciendo a la amenaza que estos últimos representaban y a algunas normas legales, como la Ley 200 de 1936, que estableció la función social de las tierras.

Justo en este momento se inicia la era del "urbanismo especulativo"; es decir, hace siete décadas se inicia un proceso en el que se han formulado todo tipo de planes, proyectos, sistemas de transporte, todos ellos "integrales", que han quedado en el "papel" y que han consumido inmensas sumas de dinero. Este "urbanismo" produjo, entre otros, proyectos como el plan regulador de Le Corbusier y Wiener y Sert, que resultó en una serie de planos y de diseños desarticulados, y como los proyectos de pretendida "renovación urbana", entre estos el de Sans Facón, de nuevo solo presente en el papel, la revitalización de Chapinero, la Nueva Santafé y otra serie de costosos planos, montajes y maquetas.
Mientras ello ocurría, dentro del campo económico, en el que frecuentemente también mucho se especula, otras políticas avanzaban, como la sugerida por el primero asesor económico de los Estados Unidos y luego del Gobierno colombiano, el economista Lauchlin Currie, quien ya en el año 1959 sugería como mecanismo para dinamizar la economía crear "ciudades dentro de la ciudad". Esta "sugerencia", hecha de la mano con organismos transnacionales, conduciría a la adopción del sistema UPAC, que causó la captación masiva de dinero del público; a la edificación sin mayores consideraciones de nuevos y cada vez más costosos sectores urbanos, y al crecimiento cada vez mayor de las ciudades, con el deterioro inherente de sus áreas centrales. Esto último abriría más recientemente paso a la "reconquista" de grandes sectores dentro de un proceso que solo ahora se hace visible.

\section{De nuevo crisis o apertura hacia los grandes intereses foráneos. ¿Un juego doble?}

Transcurridas algo más de dos décadas, y ya con la suficiente perspectiva histórica para llegar al momento actual, es preciso retroceder a los años finales de la década de los ochenta del siglo xx para observar qué ocurría en el mundo. Con anterioridad se había hecho notoria la

La ciudad de Barcelona, al igual que muchas otras ciudades europeas, no es ajena a esta situación, pero en su caso, las propias murallas, la situación política y el hecho de que todos los terrenos exteriores a la muralla se considerasen zona militar, impiden que se puedan instalar en sus alrededores las nuevas industrias debido a la prohibición de construir en ese gran espacio llano, teniendo un uso exclusivamente agrícola por parte de los payeses (campesinos) de Barcelona y las poblaciones cercanas. (...)" 
fatiga de la segunda potencia planetaria, la Unión Soviética y los países situados bajo su órbita de influencia. Con mayor anterioridad, desde finales de la década de los cincuenta, se comenzaba a abrir una nueva corriente económica y filosófica, la del neoliberalismo, que fundada en el liberalismo económico clásico y el libre mercado tenía posicionados a algunos de sus teóricos en los círculos del poder.

El avance silencioso de un nuevo tipo de colonialismo se había hecho presente en nuestro medio con suficiente anterioridad. Un estudio contratado por la Alcaldía Mayor de Bogotá a un organismo multinacional, y elaborado entre los años 1972 y 1974, señalaba que en "Bogotá se incrementaba su población en 250.000 personas al año; alcanzaría en el año de 1990 los 8,5 millones de habitantes [i?] y requeriría ya para entonces de un área de expansión hacia el occidente que para entonces ya debería de rebasar ampliamente el límite natural del río Bogotá". Igualmente, "sugería" la utilización de buses y de busetas integradas dentro de una empresa única, y la expansión del aeropuerto, que entonces era reciente y se consideraba sobredimensionado.

Sorprenden todas estas sugerencias hechas hace tanto tiempo, bajo justificaciones poco claras, pero en plena concordancia con lo que ahora está ocurriendo, mientras se contrataban y publicaban estudios de factibilidad hechos para el metro, que contratados a una universidad local en número de diecisiete costaron en conjunto 11 billones de pesos ${ }^{11}$.

Así, cuando en 1989 se derrumbó el muro de Berlín, el colapso del bloque socialista no se hizo esperar, lo que concluyó con la caída de la Unión Soviética dos años después, más todo lo que de ello habría de derivarse dentro de un mundo unipolar que ya estaba en marcha.

De este modo, no es casual que a partir del primero de estos años, y con mayor énfasis desde el segundo, el tema de los planes de ordenamiento territorial haya pasado a ocupar un primer plano a nivel mundial. El caso de Colombia es demostrativo de la incidencia de estos sucesos, y aun cuando algunos tratadistas hayan afirmado que en aquel momento se produjo una "crisis" en este sentido a nivel mundial, lo cierto es que en 1989 ya se había expedido un documento predecesor de los planes de ordenamiento territorial, y en 1991 ocurrió lo mismo con la nueva carta política que vino a liberar espacios en esta y en otras materias $^{12}$.

Surgen de esta "crisis" los planes de ordenamiento territorial como instrumentos del nuevo orden mundial, en donde las transnacionales y sus grandes intereses aparecen como principales protagonistas y determinadores, por encima incluso de las entidades e intereses nacionales.

\footnotetext{
11 Todos ellos se contrataron a la Universidad de los Andes, que a la fecha se opone al metro y apoya cada vez más al sistema de transporte masivo Transmilenio.

12 Recursos naturales, comunicaciones, espacios radio magnético y geoestacionario entre otros.
} 
Mientras todo ello ocurre, no pocos estudios sugieren que en la actualidad han disminuido los índices de pobreza y mejorado las redes de servicios, "la calidad de vida" y la gobernabilidad, nociones anteriormente desconocidas ${ }^{13}$, para "lograr" ello de manera artificiosa. La ola neoliberal ha sugerido "focalizar" una serie de recursos para atender la población en apariencia poseedora de menores recursos, lo que en realidad se ha traducido en el traslado de lo que pagan los segmentos medios de la población por concepto de impuestos y servicios públicos, lo que verdaderamente ha determinado el empobrecimiento de las clases medias, donde hoy se presenta una "pobreza oculta" en ascenso.

\section{El futuro}

El futuro que se avizora a partir de la puesta en marcha de los planes de ordenamiento territorial y de las disposiciones y efectos subsiguientes en el caso de Colombia es claro, más aún si consideramos que las últimas administraciones presidenciales han tenido un claro corte neoliberal, y han dado inexplicables e inequitativos beneficios fiscales y operativos a aquellas empresas que deseen instalarse en el país. Esto hace prever una acelerada expansión urbana con un significativo incremento de las áreas edificadas y el desplazamiento de grandes sectores de la población ubicados en las áreas urbanas centrales hacia una periferia desconocida.
Otro tipo de desplazamiento también se ha hecho evidente en las áreas otrora ocupadas por industrias que bajo "estímulos" artificiales hoy se trasladan a municipios menores, con consecuencias insospechadas para estos, dada su debilidad en infraestructura y de servicios públicos.

También, anuncios recientes como el de una inducida "bonanza minera" y los avances hechos por transnacionales que han adquirido zonas mineras y embalses (Paz del Río, hidroeléctrica del Río Prado, el Quimbo...) pronostican el ingreso de nuevas compañías que, sin ningún beneficio para el Estado ni para la población, entrarán a operar de la misma manera. Igualmente, la anunciada expansión norte de Bogotá impondrá una dinámica vertiginosa a esta área y a las localidades vecinas, y la rehabilitación y reestratificación del centro de Bogotá desplazará hacia la periferia a una población empobrecida.

Desde diversos ángulos y sin una justificación clara, en el caso de Bogotá y algunos centros de las costas Caribe y Pacífica, bajo figuras gráficas especulativas se está forzando la creación de ciudadesregión que, emulando "ejemplos" con los que justamente no se puede comparar, como lo son las áreas periféricas a Nueva York o Madrid, se persigue únicamente la apertura de estas áreas a los grandes capitales transnacionales ${ }^{14}$.

13 Entre estos, pobreza y mejoramiento integral de barrios, por Carlos Torres Tovar, y Bogotá, progreso y gobernabilidad, por Alan Gisbert.

14 En estos términos se expresa la Mesa de planificación regional Bogotá-Cundinamarca, publicada por la CAR, organismo que sólo unos pocos años atrás se encargaba de vigilar los recursos hídricos y naturales. 
En cuanto al paisaje resultante de estos procesos, será el propio de las capitales de la globalización: despersonalizadas y cubiertas de concreto, vidrios polarizados y de lugares comunes y de símbolos que se repiten aquí y allá, dejando de lado la identidad. En un futuro próximo, en estas áreas en expansión no vivirán sus pobladores tradicionales, sino que las ocuparán gentes provenientes de otros lugares, posiblemente de las potencias emergentes del Asia, cuya población desbordada invadirá un mundo que envejece.
La historia, como la política, actúa bajo ciclos pendulares, y más allá de lo previsto a corto plazo es incierto hacer especulaciones, mas la protección de los recursos naturales impone invertir el peligroso mecanismo de relojería puesto en marcha por los gobiernos que, pese a toda evidencia y únicamente animados por los beneficios personales, siguen haciendo generosas entregas a inescrupulosos empresarios. Como en tal sentido se expresó un celebrado gobernante suramericano recientemente: "es hora de invertir la marcha de este reloj”.15.

\section{Literatura citada}

Capdequí, J. M. (1946). El régimen de la tierra en la América Española durante el periodo colonial. Trujillo (R. D.): Universidad de Santo Domingo.

Castillo, G. (2006). Caminando en el tiempo. El encuentro de tres conquistadores en la sabana de Bogotá. Bogotá: Intermedio.

Gutiérrez, R. (2002). Arquitectura y urbanismo en Iberoamérica (4. ${ }^{a}$ ed.). Madrid: Cátedra.

Santa, E. (1995). Dimensión historica de la colonización antioqueña. Antioquía, Colombia: Pregón.

Wikipedia. Leyes de indias. www.nueva-acropolis.es/cultura/historia/leyes de indias [Obtenido octubre de 2010].

Wikipedia. Casa de Austria. www.es.wikipedia.org/wiki/Casa_de_Austria [Obtenido enero de 2011]

Wikipedia. Distrito del ensanche. www.es.wikipedia.org/wiki/Distrito_del_Ensanche [Obtenido octubre de 2010].

Wikipedia. Historia de Colombia. www.es.wikipedia.org/wiki/Historia_de_Colombia [Obtenido octubre de 2010].

Wikipedia. José Eustasio Rivera. www.es.wikipedia.org/wiki/ Jos\%C3\%A9_Eustasio_Rivera [Obtenido octubre de 2010].

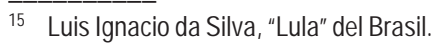

Recepción: 25 de octubre de 2010

Aprobación: 19 de noviembre de 2010

156| Mauricio Villamil Pérez 